\title{
The effect of ion flux on plasma-induced modification and deuterium retention in tungsten and tungsten-tantalum alloys
}

\author{
Y. Zayachuk k,b,c,d*, A. Manhard ${ }^{\mathrm{e}}$, M. H. J. 't Hoen ${ }^{\mathrm{f}}$, W. Jacob ${ }^{\mathrm{e}}$, P. A. Zeijlmans van Emmichoven ${ }^{\mathrm{f}, \mathrm{g}}$, \\ and G. van Oost ${ }^{\mathrm{b}}$ \\ ${ }^{\text {a SCK}} \cdot$ CEN, Trilateral Euregio Cluster, Boeretang 200, 2400 Mol, Belgium \\ ${ }^{\mathrm{b}}$ Department of Applied Physics, Ghent University, St. Pietersnieuwstraat 41, 9000 Ghent, Belgium \\ ${ }^{c}$ Department of Materials, University of Oxford, Parks Road, Oxford OX1 3PH, UK \\ ${ }^{\mathrm{d} C u l h a m ~ C e n t r e ~ f o r ~ F u s i o n ~ E n e r g y, ~ C u l h a m ~ S c i e n c e ~ C e n t r e, ~ A b i n g d o n ~ O X 14 ~ 3 D B, ~ U K ~}$ \\ ${ }^{\mathrm{e}}$ Max Planck Institute for Plasma Physics, Boltzmannstrasse 2, 85748 Garching, Germany \\ ${ }^{f}$ FOM Institute DIFFER, Trilateral Euregio Cluster, Edisonbaan 14, 3439 MN Nieuwegein, the Netherlands \\ ${ }^{\mathrm{g}}$ Aviation Academy, Amsterdam University of Applied Sciences, Weesperzijde 190, 1097 DZ Amsterdam, \\ the Netherlands
}

$\begin{array}{ll}\text { Published in: } & \text { Journal of Nuclear Materials, 464, 69-72 (2015). } \\ \text { doi: } & \text { http://dx.doi.org/10.1016/j.jnucmat.2015.04.028 }\end{array}$

Submitted: 17.07.2014

Accepted: 18.04 .2015

Available online: 24.04 .2015

The paper presents the results of an experimental study of deuterium retention in $\mathrm{W}$ and $\mathrm{W}-\mathrm{Ta}$ alloy that were exposed to first-wall relevant low flux $\left(\sim 10^{20} \mathrm{~m}^{-2} \mathrm{~s}^{-1}\right)$ deuterium plasma in the ECR plasma generator PlaQ. Subsequent analysis included surface imaging by optical microscopy, deuterium depth profiling by nuclear reaction analysis (NRA) and measurements of deuterium content by thermal desorption spectroscopy (TDS). It was found that under investigated exposure conditions the deuterium content was higher in $\mathrm{W}-\mathrm{Ta}$ alloy than in W. Combined with the previously reported results showing that under high-flux $\left(\sim 10^{24} \mathrm{~m}^{-2} \mathrm{~s}^{-1}\right)$ retention is higher in $\mathrm{W}$ instead, this gives rise to a peculiar flux effect - dependence of relative retention between different materials on exposure flux. We interpret this effect as evidence that at different flux ranges different populations of trapping sites determine the retention, namely pre-existing microstructural traps at low-flux exposure and plasma-induced ones at high-flux exposure.

Keywords: Deuterium retention, Pilot-PSI, tungsten, tungsten-tantalum

\section{Introduction}

Tungsten is suggested to be used as a divertor material in ITER and possibly as a first wall material in future fusion reactors. Tungsten is known to have certain unfavorable properties hindering its use as a plasma-facing material (PFM), such as susceptibility to surface cracking under ELM-like transient heat loads [1] due to the high brittle-to-ductile transition temperature [2]. Several alloys were proposed with advantageous thermo-mechanical properties, one of such alloys being W-Ta [3], which was demonstrated to have better resistance to degradation under repetitive ELM-like heat loads [4].

It is known that exposure of tungsten-based materials to deuterium plasma leads to modification of these materials. It can manifest itself by the formation of subsurface cavities associated with surface blisters [5], [6], as well as by the generation of atomic defects [7]. Plasma-induced material modification was also found to significantly influence deuterium retention, leading to the emergence of a history effect - the enhancement of the deuterium retention after the pre-exposure to low-energy, high-flux deuterium plasma [8].

Reports concerning deuterium retention in $\mathrm{W}$ $\mathrm{Ta}$ available in the literature were initially contradictory (compare, for example, [9] and [10]). These contradictory results were pointed out to originate in the different ion fluxes where the studies were performed. In our previous publication [9], we suggested that the discrepancy might be explained by the difference in dynamics of plasmainduced defect formation that depends on ion flux.

These considerations were the motivation for the present work. In this contribution we present the results of the measurements of retention in $\mathrm{W}$ and $\mathrm{W}-\mathrm{Ta}$ exposed to first-wall relevant low-flux plasma. We compare this to the earlier published results on retention in the same material grades performed at divertor-relevant high-flux exposure conditions. In addition, the interaction of low-flux plasma with materials pre-exposed to high-flux plasma is investigated, providing an indication of the difference between processes of deuterium uptake at low and high plasma fluxes. 


\section{Experiment}

Powder metallurgical $\mathrm{W}$ and W-Ta alloy, containing 5 mass $\%$ of $\mathrm{Ta}$, both provided by Plansee, were investigated. All investigated polycrystalline samples were mechanically polished to mirror finish with $0.05 \mu \mathrm{m}$ alumina polishing suspension, and then annealed in vacuum at $1300 \mathrm{~K}$ for 1 hour. During annealing the samples were not recrystallized. The samples were discs with a diameter of $20 \mathrm{~mm}$ and a thickness of $1 \mathrm{~mm}$.

The low-flux exposures were performed at the electron cyclotron resonance (ECR) plasma generator $\mathrm{PlaQ}$ at the Max Planck Institute for Plasma Physics (Garching, Germany). Details of the design and operation of the device can be found in [11]. The energy of the ions arriving at the sample's surface is determined by a floating potential (no additional bias was applied), established at $\sim 15 \mathrm{~V}$. The majority of ion flux is carried by $\mathrm{D}^{3+}$ ions, which means that the energy per deuteron is equal to one third of the ion energy, $\sim 5 \mathrm{eV}$. The exposure conditions were the following: ion flux $\sim 5^{*} 10^{19} \mathrm{~m}^{-2} \mathrm{~s}^{-1}$, surface temperature $300 \mathrm{~K}$ (RT), and duration of exposure 48 hours, corresponding to a fluence of $\sim 10^{25} \mathrm{~m}^{-2}$.

Two sets of samples were exposed. The first consisted of $\mathrm{W}$ and $\mathrm{W}-\mathrm{Ta}$ samples which were polished and thermally treated but not previously exposed to plasma (referred to as "reference samples"). The second set consisted of W and WTa samples which were previously exposed to high fluences $\left(\sim 10^{27} \mathrm{~m}^{-2}\right)$ of high-flux $\left(\sim 10^{24} \mathrm{~m}^{-2} \mathrm{~s}^{-1}\right)$ deuterium plasma at surface temperature of $\sim 450 \mathrm{~K}$, and subsequently degassed (referred to as "preexposed samples").

Imaging of the surfaces after plasma exposure was performed using optical microscopy.

For the deuterium depth profiling we implemented the commonly used $\mathrm{D}\left(\mathrm{He}^{3} ; \mathrm{p}\right) \alpha$ reaction. The use of this reaction for the investigation of D in tungsten is described in [12]. The energies used for the detailed depth profiling were $500 \mathrm{keV}, 690 \mathrm{keV}, 1.2 \mathrm{MeV}, 1.8 \mathrm{MeV}, 2.4$ $\mathrm{MeV}$, and $3.2 \mathrm{MeV}$. The reconstruction of depth profiles from raw NRA data (alpha and proton energy spectra) was performed with the use of the software packages SimNRA [13] and NRADC [14].

Total retention was measured with TDS. The maximum temperature during the run was $1273 \mathrm{~K}$, the temperature ramp $0.5 \mathrm{~K} / \mathrm{s}$, and the holding time at the maximum temperature 5 minutes. The release fluxes of molecular $\mathrm{HD}$ and $\mathrm{D}_{2}$ were measured by a quadrupole mass spectrometer.

The experimental sequence was the following. The samples - reference and pre-exposed ones were exposed to low-flux deuterium plasma in PlaQ. After the exposures the surfaces of the samples were imaged in order to investigate whether any surface structures had formed. Subsequently, the deuterium depth profiles were reconstructed using NRA. Finally, the samples were degassed in TDS runs while recording deuterium release spectra.

\section{Experimental results}

\subsection{Surface imaging}
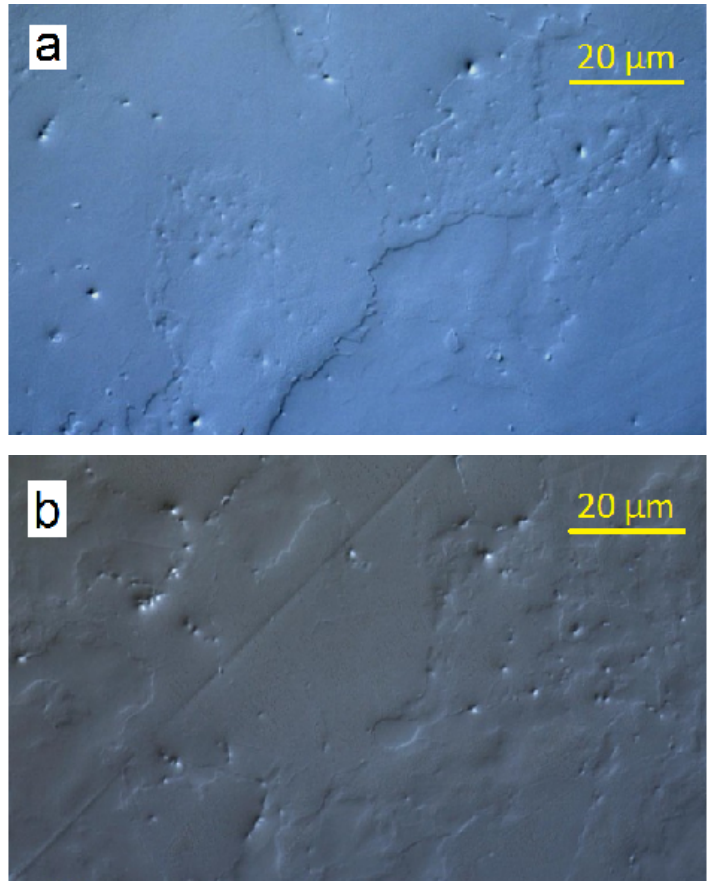

Fig. 1 Optical images of the surfaces of the reference samples: (a) W, (b) W-Ta.

Fig. 1 shows the surface images of the reference $\mathrm{W}$ and $\mathrm{W}-\mathrm{Ta}$ samples after exposure to low-flux plasma in PlaQ. It can be seen that neither material exhibits characteristic plasma-induced features such as blisters: only polishing morphology is visible.

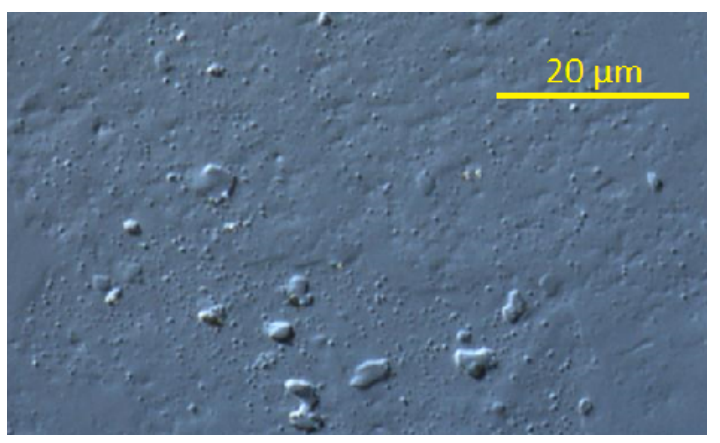

Fig. 2 Optical image of the surface of the pre-exposed $\mathrm{W}$ sample.

The pre-exposed samples feature surface blistering, with $\mathrm{W}$ having higher number and larger size of blisters as compared to W-Ta (see [9]). Exposure of these pre-exposed samples to low-flux plasma did not lead to any noticeable changes of their surfaces (Fig. 2; compare to Fig. 3 in [9]). 


\subsection{Results of NRA depth profiling}

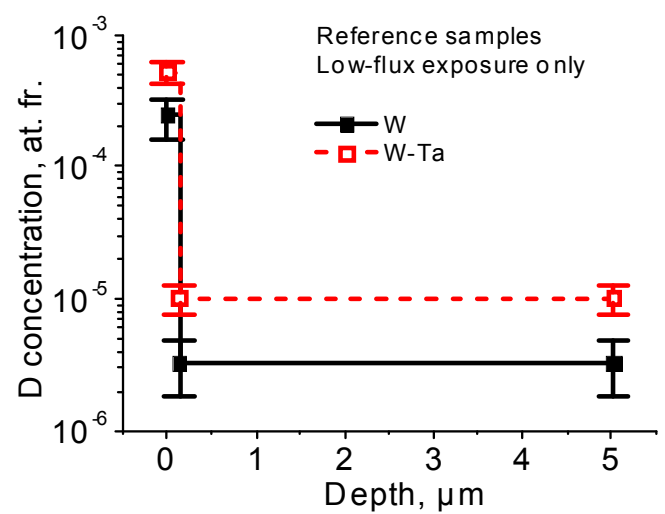

Fig. $3 \mathrm{D}$ depth profiles in the reference $\mathrm{W}$ and $\mathrm{W}-\mathrm{Ta}$ samples.

Fig. 3 shows the results of NRA deuterium depth profiling performed on the samples exposed only to low-flux plasma in PlaQ. It should be noted that reconstruction of the deuterium depth profiles in these samples is not easily possible because the number of measurement counts was very low (indicating that the amount of deuterium within these samples was very low). Inadequate counting statistics means that it is difficult for NRADC software to perform the fit of the simulated energy spectra to the experimentally measured ones. Eventually only an indication of the deuterium contents in the regions close to the surface and in the bulk can be obtained. However, this is enough to show that the deuterium content is higher in $\mathrm{W}$ $\mathrm{Ta}$ than in $\mathrm{W}$ in both regions by about a factor of 2 to 4 .

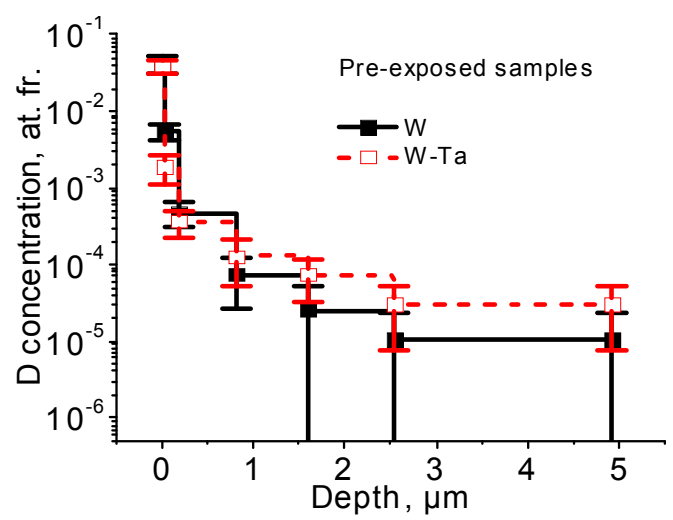

Fig. $4 \mathrm{D}$ depth profiles in the pre-exposed $\mathrm{W}$ and $\mathrm{W}-\mathrm{Ta}$ samples.

Fig. 4 shows the depth distributions of the deuterium concentrations in the $\mathrm{W}$ and $\mathrm{W}-\mathrm{Ta}$ samples exposed to low-flux plasma in $\mathrm{PlaQ}$ after pre-exposure to high-flux plasma and subsequent degassing. It is evident that close to the surface the deuterium content is higher by up to a factor of $\sim 3$, in $\mathrm{W}$ than in W-Ta. On the other hand, at larger depths the deuterium content in W-Ta is somewhat higher than in W. It should be also emphasized that over the entre probed range the deuterium content in pre-exposed samples is higher (at smaller depths) or comparable within the experimental error (at larger) to reference ones, both for $\mathrm{W}$ and $\mathrm{W}-\mathrm{Ta}$ (compare Fig. 3 and 4).

\subsection{Results of TDS}

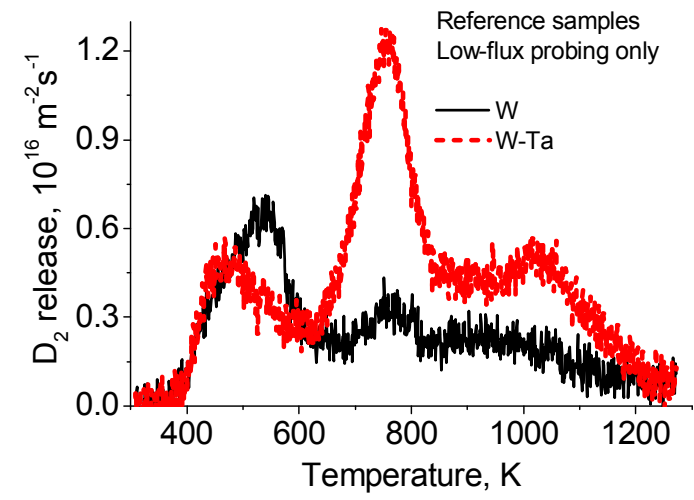

Fig. 5 TDS spectra of the reference $\mathrm{W}$ and W-Ta samples.

Fig. 5 shows the comparison of TDS spectra measured on the samples exposed to low-flux plasma in PlaQ only. It is evident that there is a significant difference in shape between $\mathrm{W}$ and $\mathrm{W}$ Ta. Both feature two well-separated release peaks: these are located at $\sim 530 \mathrm{~K}$ and $\sim 760 \mathrm{~K}$ in case of $\mathrm{W}$, and $\sim 470 \mathrm{~K}$ and $\sim 750 \mathrm{~K}$ in case of W-Ta. Both spectra feature also a long release tail stretching into the high-temperature region almost to the end of the temperature ramp. For W-Ta, on top of this tail an additional, albeit low, release peak is discernible at $\sim 1020 \mathrm{~K}$. While the low-temperature peak is roughly of the same height for both materials, the high-temperature peak of $\mathrm{W}-\mathrm{Ta}$ at $\sim 750 \mathrm{~K}$ is much higher than the corresponding peak of $\mathrm{W}$. Total deuterium retention is higher in $\mathrm{W}-\mathrm{Ta}$ as compared to $\mathrm{W}-7 * 10^{18}$ and $4.8^{*} 10^{18} \mathrm{D} / \mathrm{m}^{2}$, respectively. While the low-temperature peak dominates the release in case of $\mathrm{W}$, in case of $\mathrm{W}-\mathrm{Ta}$ the peak at $\sim 750 \mathrm{~K}$ is predominant.

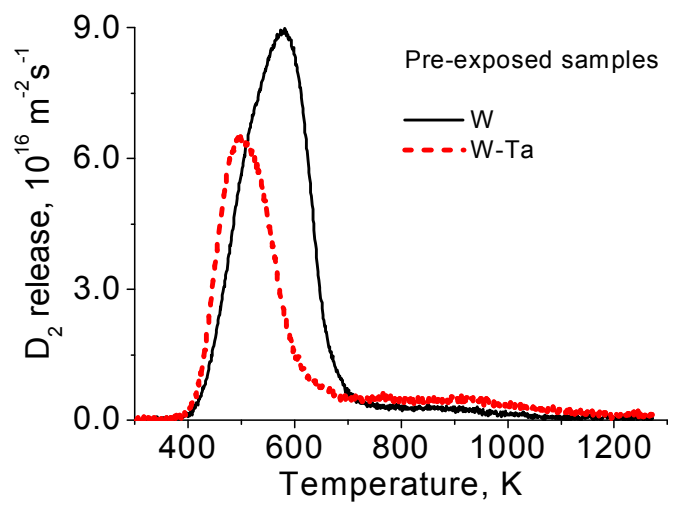

Fig. 6 TDS spectra of the pre-exposed samples of $\mathrm{W}$ and W-Ta.

Fig. 6 shows the comparison of the desorption spectra from the $\mathrm{W}$ and $\mathrm{W}-\mathrm{Ta}$ samples which had the history of high-flux pre-exposure. 
Both $\mathrm{W}$ and $\mathrm{W}$-Ta yield only one release peak. The maximum release occurs at somewhat lower temperature in case of $\mathrm{W}-\mathrm{Ta}-\sim 500 \mathrm{~K}$, while in case of $\mathrm{W}$ this maximum is located at $\sim 580 \mathrm{~K}$. The total integrated amount is higher in case of $\mathrm{W}$ as compared to W-Ta $\left(\sim 2.9 * 10^{19}\right.$ and $\sim 2.1 * 10^{19} \mathrm{D} / \mathrm{m}^{2}$, respectively). It should be noted that, similarly to the spectra of the reference samples, the spectra of the pre-exposed samples feature a long tail stretching towards high temperatures (above 1000 $\mathrm{K})$.

\section{Discussion}

The major experimental result of this work is that for samples exposed to low ion flux conditions $\left(\sim 10^{20} \mathrm{~m}^{-2} \mathrm{~s}^{-1}\right)$ only, the deuterium retention is higher in W-Ta than in W.

The observed difference in retention between $\mathrm{W}$ and W-Ta at low exposure flux $\left(\sim 10^{20} \mathrm{~m}^{-2} \mathrm{~s}^{-1}\right)$, combined with earlier reported results on retention in identical grades of materials exposed to high exposure flux $\left(\sim 10^{24} \mathrm{~m}^{-2} \mathrm{~s}^{-1}\right)$, gives rise to a peculiar "flux effect". It manifests itself in the fact that under low-flux exposure conditions retention in WTa alloy is higher than in $\mathrm{W}$, while at high-flux exposure conditions retention is higher in $\mathrm{W}$ than in W-Ta. Its existence shows that depending on the exposure flux, different materials have different dynamics of deuterium accumulation. This indicates that predominant trapping mechanisms, at low and high exposure fluxes may be different.

It seems reasonable to assume that at low exposure flux conditions material modification is much weaker (i.e. the concentration of plasmainduced trapping sites is much lower) as compared to the high-flux exposure. The evidence for this is the fact that surface imaging did not reveal any noticeable plasma-generated surface structures (Fig. 1), unlike the high-flux exposure scenario (Fig. 2). Thus, the bulk (by which we mean the region beyond $\sim 14 \mathrm{~nm}$ from the surface) deuterium concentration as measured by NRA (Fig. 3) can be used as an indication of the "natural" - i.e. not related to plasma impact - concentration of preexisting trapping sites. These are assumed to exist throughout the material, while their concentration is determined by material's microstructure. We point out that the immediate near-surface region, i.e., the first $\sim 14 \mathrm{~nm}$ below the surface, is probably still somewhat modified by the plasma impact. From the observations described above it follows that this natural trap concentration is higher in W-Ta than in $\mathrm{W}$ (atomic fraction $\sim 10^{-5}$ and $\sim 2 * 10^{-6}$, respectively).

In our earlier report [9] we discussed that under the high-flux exposure conditions described there, retention is strongly influenced by the plasmainduced material modification. Consequently, at those conditions $\mathrm{W}$ features higher retention because of more significant plasma-induced modification, i.e., a higher concentration of plasma- induced traps, than W-Ta. In this respect it is important to note that the effect caused by the highflux plasma exposure is at least partly permanent: pre-exposed $\mathrm{W}$ retains more deuterium than $\mathrm{W}-\mathrm{Ta}$ after low-flux exposure (see Fig. 6 and Fig. 4).

\section{Conclusions}

This paper presented the results - surface imaging, TDS and NRA measurements - of low ion flux $\left(\sim 10^{20} \mathrm{~m}^{-2} \mathrm{~s}^{-1}\right)$ deuterium plasma exposure of $\mathrm{W}$ and $\mathrm{W}-5 \%$ Ta samples. Surface imaging indicated that no noticeable material modification was induced in the investigated material during the exposure. TDS and NRA measurements of the deuterium content in the exposed samples showed that under these conditions the deuterium content is higher in W-Ta as compared to W. Combined with our earlier results on retention in the same materials exposed to high-flux plasma $\left(\sim 10^{24} \mathrm{~m}^{-2} \mathrm{~s}^{-1}\right)$, this gives rise to a peculiar "flux effect" $-\mathrm{W}$ features higher retention at high exposure flux than W-Ta, but lower retention at low flux. We explain this effect as follows: at low exposure flux, the plasmainduced material modification is insignificant and thus trapping is dominated by the population of preexisting traps, which we find to be higher in W-Ta in agreement with [10]. On the other hand, at high exposure flux, the retention is dominated by plasma-induced traps, whose concentration is, according to our observations, higher in W.

\section{Acknowledgements}

This work, supported by the European Communities under the contract of Associations between EURATOM and SCK $\cdot \mathrm{CEN}$, was carried out within the framework of the European Fusion Development Agreement. The views and opinions expressed herein do not necessarily reflect those of the European Commission.

The authors would like to express gratitude to J. Dorner and M. Fußeder (Max Planck Institute for Plasma Physics) for their help with NRA measurements.

\section{References}

[1] T. Hirai, G. Pintsuk, J. Linke, M. Batilliot, J. Nucl. Mater. 390-391 (2009) 751-754.

[2] P. Gumbsch, J. Nucl. Mater. 323 (2003) 304-312.

[3] J. Linke, T. Loewenhoff, V. Massaut, G. Pintsuk, G. Ritz, M. Rodig, A. Schmidt, C. Thomser, I. Uytdenhouwen, V. Vasechko and M. Wirtz, Nucl. Fusion 51 (2011) 073017.

[4] M. Wirtz, J. Linke, G. Pintsuk, L. Singheiser and I. Uytdenhouwen, Phys. Scr. T145 (2011) 014058.

[5] W. Wang, J. Roth, S. Lindig and C. H. Wu, J. Nucl. Mater. 299 (2001) 124-131.

[6] S. Lindig, M. Balden, V.Kh. Alimov, T. Yamanishi, W.M. Shu, J. Roth, Phys. Scr. T138 (2009) 014040 . 
[7] O. V. Ogorodnikova, J. Roth, and M. Mayer, J. Nucl. Mater. 313 (2003) 469.

[8] Y. Zayachuk, M. H. J. 't Hoen, P. A. Zeijlmans van Emmichoven, I. Uytdenhouwen, and G. van Oost, Nucl. Fusion 52 (2012) 103021.

[9] Y. Zayachuk, M. H. J. 't Hoen, P. A. Zeijlmans van Emmichoven, D. Terentyev, I. Uytdenhouwen, and G. van Oost, Nucl. Fusion 53 (2013) 013013.

[10] K. Schmid, V. Rieger, A. Manhard, J. Nucl. Mater., 426 (2012) 247-253.

[11] A. Manhard, T. Schwarz-Selinger and W. Jacob, Plasma Sources Science and Technology 20 (2011) 015010.

[12] V.Kh. Alimov, M. Mayer, J. Roth, Nuclear Instruments and Methods in Physics Research B 234 (2005) 169-175.

[13] M. Mayer, SimNRA User Guide, Report IPP 9/113, Max-Planck-Institut für Plasmaphysik, Garching, Germany, 1997.

[14] K. Schmid and U. von Toussaint, Nucl. Instr. Meth. in Phys. Res. B 281 (2012) 64-71. 